DOI: $10.5216 /$ cab.v14i3.17170

\title{
AVALIAÇÃO DE EMBRIÕES OVINOS PROVENIENTES DE OÓCITOS SUBMETIDOS A ESTRESSE CALÓRICO DURANTE A MATURAÇÃO IN VITRO
}

\author{
EdIVALdO Rosas dos SANTOS JUNIOR ${ }^{1}$; RICARDO MACÊDO CHAVES ${ }^{2}$; JOSÉ CARLOS FERREIRA DA \\ SILVA ${ }^{4}$; MARCELO TIGRE MOURA ${ }^{4}$; CLÁUdIO COUTINHO BARTOLOMEU ${ }^{4}$; PAULO BAYARD DiAS \\ GONÇALVES $^{3}$; PAULO FERNANDES DE LIMA ${ }^{4}$; MARCOS ANTÔNIO LEMOS DE OLIVEIRA ${ }^{4}$ \\ ${ }^{1}$ Universidade Federal Rural de Pernambuco, Unidade Acadêmica de Serra Talhada, Serra Talhada - PE, Brasil \\ edivaldorosas@gmail.com* \\ ${ }^{2}$ Laboratório de Reprodução Animal - Universidade Estadual do Maranhão, São Luis - MA, Brasil \\ ${ }^{3}$ Universidade Federal de Santa Maria, Av. Roraima no 1000 - Cidade Universitária - Bairro Camobi - Santa \\ Maria - RS, Brasil \\ ${ }^{4}$ Laboratório de Biotécnicas da Reprodução do Departamento de Medicina Veterinária \\ Universidade Federal Rural de Pernambuco, Dois Irmãos s/n, Recife-PE, Brasil.
}

\section{RESUMO}

Neste trabalho foi avaliado o efeito do estresse calórico durante a maturação de oócitos sobre a produção in vitro de embriões ovinos. Os ovários foram obtidos em abatedouro e os oócitos colhidos de folículos de 2 a $6 \mathrm{~mm}$ de diâmetro. Após seleção, os oócitos, em 10 replicações, foram colocados para maturação in vitro (MIV) durante 24 horas. Os oócitos submetidos ao estresse térmico de $41^{\circ} \mathrm{C}$ durante $3,6,12,18$ e 24 horas foram posteriormente transferidos para completar a MIV a $39{ }^{\circ} \mathrm{C}$, mesma temperatura utilizada para maturação dos oócitos do grupo controle. $\mathrm{O}$ desenvolvimento dos embriões foi determinado nos dias $3,4,5$ e 8 pós-fecundação. A avaliação da qualidade dos embriões foi efetuada através da contagem total de células coradas pelo DAPI e da determinação do número de blastômeros positivos para apoptose através do teste de TUNEL. Observou-se que o estresse térmico diminuiu $(\mathrm{P}<0,05)$ a capacidade de maturação dos oócitos de acordo com o tempo de exposição à temperatura de $41^{\circ} \mathrm{C}$. No grupo de oócitos incubados a $39^{\circ} \mathrm{C}, 70,70 \%$ maturou, enquanto que nos grupos expostos ao estresse térmico, apenas $45,28 \%$, $35,17 \%, \quad 12,30 \%, \quad 9,74 \%$ e $4,60 \%$ maturaram, respectivamente, após $3,6,12,18$ e 24 horas de incubação. A duração de exposição dos oócitos ao estresse calórico foi inversamente proporcional $(\mathrm{P}<0,05)$ à capacidade de desenvolvimento embrionário e diretamente proporcional $(\mathrm{P}<0,05)$ ao número de blastocistos positivos para apoptose. Todavia, o efeito deletério do estresse térmico sobre a clivagem e os embriões nos estádios de 8 a 16 células e de mórula foi crescente $(\mathrm{P}>$ $0,05)$ somente até 18 horas de incubação. Os resultados permitem concluir que o estresse calórico durante a maturação in vitro de oócitos reduz a quantidade e a qualidade dos embriões ovinos produzidos in vitro determinadas pela alta incidência de apoptose.

PALAVRAS-CHAVE: blastocisto; FIV; MIV; PIV.

\section{EVALUATION OF SHEEP OOCYTES SUBMITTED TO HEAT STRESS DURING IN VITRO MATURATION}

\section{ABSTRACT}

The aim of this work was to evaluate the effect of heat stress during oocyte maturation on ovine in vitro embryo production. Ovaries were collected at abattoirs and oocytes retrieved from follicles ranging from 2 and $6 \mathrm{~mm}$ in diameter. After selection, all oocytes, in 10 replicates, were placed in in vitro maturation (IVM) during 24 hours. The oocytes were submitted to heat stress at $41^{\circ} \mathrm{C}$ during $3,6,12,18$ and 24 hours and were further transferred to 
$39^{\circ} \mathrm{C}$ in order to complete IVM, which was the temperature of maturation of control oocytes. Embryonic development was determined on days $3,4,5$, and 8 postfertilization. Embryo evaluation was performed as total cell count by DAPI staining and determination of positive blastomere for apoptosis by the TUNEL assay. We observed that heat stress diminishes $(\mathrm{P}<0.05)$ oocyte maturation capacity in accordance with exposure time at $41^{\circ} \mathrm{C}$. In the group of oocytes incubated at $39^{\circ} \mathrm{C}, 70.70 \%$ matured, while in the groups exposed to heat stress at $41^{\circ}$ C, only $45.28 \%, 35.17 \%, 12.30 \%, 9.74 \%$ and $4.60 \%$ matured after $3,6,12,18$ and 24 hours of incubation,

KEYWORDS: blastocyst; IVF; IVM; IVP.

\section{INTRODUÇÃO}

A cadeia produtiva da ovinocultura do Nordeste brasileiro já mostrou sua potencialidade como uma atividade que se adapta bem às adversas condições climáticas da região, que é reconhecida pelo potencial para produção de carne e pele ovina (SIMPLÍCIO et al., 2007). A elevada temperatura no ambiente é um dos principais fatores responsáveis pela redução da fertilidade de animais criados em fazendas (HANSEN, 2009). Tem sido relatado que a viabilidade de oócitos e de embriões bovinos é menor durante as estações quentes do que na época fria (ROTH, 2008; EDWARDS et al., 2009). Essa depressão estacional do desempenho reprodutivo pode ser determinada por múltiplos fatores, incluindo manejo, ambiente inadequado, idade $\mathrm{e}$ sensibilidade espécie-específica a esses fatores (BADINGA et al., 1985).

Estudos in vitro têm demonstrado também que o estresse calórico tem efeito negativo sobre a viabilidade e a capacidade de desenvolvimento de embriões mamíferos (JU et al., 1999; PAULALOPES \& HANSEN, 2002ab; TSENG et al., 2004; ROTH, 2008; HANSEN, 2009).

Diante do abordado, avaliou-se o efeito do estresse calórico durante a maturação de oócitos sobre a produção in vitro de embriões ovinos, objetivando fornecer dados relacionados aos mecanismos de morte celular e redução da competência de oócitos de animais naturalmente expostos à elevada temperatura ambiente.

\section{MATERIAL E MÉTODOS}

Os ovários foram obtidos de fêmeas ovinas em abatedouro localizado na Região Metropolitana respectively. The duration of exposure to heat stress was inversely proportional $(\mathrm{P}<0.05)$ to embryonic developmental capacity and directly proportional $(\mathrm{P}<$ 0.05 ) to the number of blastocysts positive to apoptosis. However, the cleavage rate and embryonic development from 8 to 16 cells and morulae stages were affected by heat stress $(\mathrm{P}>0.05)$ only up to 18 hours of incubation. The results allow the conclusion that heat stress during oocyte in vitro maturation reduces the quantity and quality of ovine embryos produced in vitro determined by the high incidence of apoptosis.

da cidade do Recife - PE que apresenta, como coordenadas geográficas, latitude $08^{\circ} 03^{\prime} 14^{\prime \prime} \mathrm{S}$ e longitude $34^{\circ} 52^{\prime} 52^{\prime \prime} \mathrm{W}$. Na estação seca, outubro de 2009 a março de 2010, a temperatura ambiente variou de 23 a $33^{\circ} \mathrm{C}$ e a umidade relativa média foi de $71 \%$. Na estação chuvosa, abril a setembro de 2010 , a temperatura oscilou de 18 a $31^{\circ} \mathrm{C}$ e a umidade relativa média foi de $85 \%$ durante o ano de 2009 (INMET, 2009).

No período máximo de uma hora após o abate, os ovários foram transportados ao laboratório em garrafa térmica contendo solução fisiológica a $30^{\circ} \mathrm{C}$, que foi acrescida de $30 \mathrm{~g} \mathrm{~mL}^{-1}$ de sulfato de gentamicina. Os oócitos, colhidos de folículos ovarianos medindo de 2 a $6 \mathrm{~mm}$ de diâmetro, foram depositados em placa de Petri contendo o meio de colheita constituído por 8,0 $\mathrm{mg}$ de bicarbonato de sódio, 45,0 mg de glicose, 5,6 mg de piruvato de sódio, 11,9 mg de HEPES, $2,5 \mathrm{mg}$ de sulfato de gentamicina e $20,0 \mathrm{mg}$ de álcool polivinílico em $50 \mathrm{~mL}$ de TALP.

Imediatamente após a seleção e com base na classificação morfológica descrita por CHIAMENTI et al. (2013), os oócitos, em 10 réplicas, foram lavados três vezes no meio de colheita e distribuídos nas gotas de $100 \mu \mathrm{L}$ do meio de maturação in vitro constituído pelo TCM 199 , suplementado com $50 \mathrm{~g} \mathrm{~mL}^{-1}$ de piruvato de sódio, 2,6 mg mL $\mathrm{mg}^{-1}$ de bicarbonato de sódio, $10 \%$ de soro fetal bovino (SFB), $50 \mathrm{~g} \mathrm{~mL}^{-1}$ de sulfato de gentamicina, $20 \mu \mathrm{g} \mathrm{mL}^{-1}$ de FSH/LH (Pluset $\left.{ }^{\circledR}\right)$ e 1 $\mathrm{mg} \mathrm{mL}^{-1}$ de álcool polivinílico.

A maturação in vitro foi realizada durante 24 horas em atmosfera úmida contendo $5 \%$ de $\mathrm{CO}_{2}$. Os oócitos do grupo controle foram incubados à temperatura de $39^{\circ} \mathrm{C}$ e os submetidos ao estresse calórico de $41^{\circ} \mathrm{C}$ durante $3,6,12,18$ e 24 horas de incubação, com exceção do grupo de 
24 horas, foram posteriormente transferidos para outra estufa à temperatura de $39^{\circ} \mathrm{C}$ para completar a maturação in vitro.

Ao término do período de maturação in vitro, procedeu-se à seleção dos oócitos, com base na expansão das células do cumulus (CHIAMENTI et al., 2013), para exposição aos espermatozóides tratados com meio definido modificado (mDM), segundo KESKINTEPE et al. (1998). O referido meio foi constituído de 0,1250 $\mathrm{g}$ de glicose, $0,1552 \mathrm{~g}$ de bicarbonato de sódio, $0,0069 \mathrm{~g}$ de piruvato de sódio, $0,0500 \mathrm{~g}$ de álcool polivinílico, $0,0500 \mathrm{~g}$ de cafeína e $50 \mu \mathrm{g} \mathrm{mL}^{-1} \mathrm{de}$ gentamicina em $50 \mathrm{~mL}$ do mDM. A fecundação in vitro foi realizada com sêmen fresco na concentração espermática de $2 \times 10^{6} / \mathrm{mL}$.

Decorridas 18 horas da incubação, os possíveis zigotos foram desnudados e transferidos para gotas de $100 \mu \mathrm{L}$ do fluido sintético de oviduto modificado, suplementado com $10 \%$ de SFB. Os possíveis zigotos foram incubados a $39^{\circ} \mathrm{C}$ em atmosfera úmida contendo $5 \%$ de $\mathrm{CO}_{2}, 5 \%$ de $\mathrm{O}_{2} \mathrm{e}$ $90 \%$ de $\mathrm{N}_{2}$ durante oito dias, dependendo do grupo experimental. Ressalta-se que as avaliações foram efetuadas no terceiro dia (D-3) quanto à clivagem, no quarto (D-4) dos embriões com 8 a 16 células, no quinto (D-5) daqueles no estádio de mórula e no oitavo dia (D-8) dos blastocistos.

Após o período de cultivo embrionário, a qualidade dos blastocistos foi avaliada por meio da contagem total de células com o corante DAPI e a avaliação da fragmentação de DNA foi realizada através do teste "terminal deoxynucleotidyl transferase-mediated dUTP nick and labeling" (TUNEL), conforme recomendação de PAULALOPES \& HANSEN (2002a), bem como de ROTH \& HANSEN (2004). As avaliações acima descritas foram realizadas com auxílio de um microscópio de fluorescência, com aumento de 1000x.
A estatística foi realizada através da análise de variância pelo método dos quadrados mínimos. Os resultados foram expressos em média e desvio-padrão (análise de variância entre grupos). Os dados em porcentagens foram transformados para arco seno da raiz quadrada de $\mathrm{x} / 100$ e submetidos à análise de variância e ao teste $\mathrm{F}$ para variâncias a $5 \%$ de significância. Os dados foram transformados e não foram analisados por um método não-paramétrico para preservar o modelo experimental. Em seguida, um teste t de Student para comparação entre médias foi realizado, a 5\% de significância, para variâncias equivalentes ou variâncias distintas, conforme o que foi verificado no teste F para variância.

\section{RESULTADOS}

$\mathrm{Na}$ Tabela 1 pode ser observado que o estresse calórico diminuiu $(\mathrm{P}<0,05)$ a capacidade de maturação dos oócitos de acordo com o tempo de exposição à temperatura de $41^{\circ} \mathrm{C}$. No grupo de oócitos incubados a $39^{\circ} \mathrm{C}, 70,70 \%$ deles maturou, enquanto que os oócitos expostos ao estresse térmico de $41^{\circ} \mathrm{C}$, apenas 45,28\%, 35,17\%, $12,30 \%, 9,74 \%$ e $4,60 \%$ maturaram nos grupos incubados por 3, 6, 12, 18 e 24 horas, respectivamente.

Os dados contidos na Tabela 2 revelam que a duração de exposição dos oócitos ao estresse calórico é inversamente proporcional $(\mathrm{P}<0,05)$ à capacidade de desenvolvimento embrionário até o estádio de blastocisto e diretamente proporcional $(\mathrm{P}<0,05)$ ao número de blastocistos positivos para apoptose $(\mathrm{P}<0,05)$. Todavia, o efeito deletério do estresse térmico sobre a clivagem e os embriões nos estádios de 8 a 16 células e de mórula foi semelhante $(\mathrm{P}>0,05)$ somente até 18 horas de incubação.

Tabela 1: Valores médios ( $\bar{x} \pm \mathrm{s}$ ) de oócitos ovinos selecionados e colocados para maturação in vitro (MIV) a $39^{\circ} \mathrm{C}$ por 24 horas e a $41^{\circ} \mathrm{C}$ por $3,6,12,18$ e 24 horas de estresse térmico e selecionados para fecundação in vitro (FIV)

\begin{tabular}{lcccccc}
\hline & MIV $39^{\circ} \mathrm{C}$ & \multicolumn{5}{c}{ MIV $41^{\circ} \mathrm{C}$} \\
\cline { 2 - 7 } Oócitos & $\begin{array}{c}24 \text { horas } \\
(\bar{x} \pm \mathrm{s})\end{array}$ & $\begin{array}{c}3 \text { horas } \\
(\bar{x} \pm \mathrm{s})\end{array}$ & $\begin{array}{c}\text { 6 horas } \\
(\bar{x} \pm \mathrm{s})\end{array}$ & $\begin{array}{c}\text { 6 horas } \\
(\bar{x} \pm \mathrm{s})\end{array}$ & $\begin{array}{c}18 \text { horas } \\
(\bar{x} \pm \mathrm{s})\end{array}$ & $\begin{array}{c}24 \text { horas } \\
(\bar{x} \pm \mathrm{s})\end{array}$ \\
\hline $\begin{array}{l}\text { Selecionados } \\
\text { para MIV }\end{array}$ & $107,2 \pm 5,22$ & $110,4 \pm 5,66$ & $106,7 \pm 4,92$ & $100,8 \pm 4,28$ & $101,6 \pm 4,16$ & $99,8 \pm 5,73$ \\
Maturados & $75,8 \pm 4,54^{\mathrm{a}}$ & $50,0 \pm 3,74^{\mathrm{b}}$ & $35,4 \pm 3,77^{\mathrm{c}}$ & $12,4 \pm 1,71^{\mathrm{d}}$ & $9,9 \pm 1,59^{\mathrm{e}}$ & $4,6 \pm, 96^{\mathrm{f}}$ \\
\hline
\end{tabular}

Valores com letras sobrescritas diferentes na mesma linha são diferentes $(\mathrm{P}<0,05)$ pelo teste $\mathrm{t}$ de Student. 
Tabela 2: Valores médios ( $\bar{x} \pm \mathrm{s}$ ) de clivagem (D-3), de embriões com 8 a 16 células (D-4), de mórulas (D5) e de blastocistos (D-8), bem como de blastocistos positivos para apoptose após maturação in vitro (MIV) de oócitos ovinos por 24 horas a $39^{\circ} \mathrm{C}$ e a $41^{\circ} \mathrm{C}$ por $3,6,12,18$ e 24 horas de estresse térmico

\begin{tabular}{|c|c|c|c|c|c|c|}
\hline \multirow[b]{2}{*}{ Embriões } & \multirow{2}{*}{$\begin{array}{c}\text { MIV } 39^{\circ} \mathrm{C} \\
24 \text { horas } \\
\left(\bar{x}_{ \pm \mathrm{s}}\right)\end{array}$} & \multicolumn{5}{|c|}{$\mathrm{MIV} 41^{\circ} \mathrm{C}$} \\
\hline & & $\begin{array}{l}3 \text { horas } \\
\left(\bar{x}_{ \pm s}\right)\end{array}$ & $\begin{array}{l}6 \text { horas } \\
\left(\bar{x}_{ \pm s}\right)\end{array}$ & $\begin{array}{c}12 \text { horas } \\
\left(\bar{x}_{ \pm s}\right)\end{array}$ & $\begin{array}{l}18 \text { horas } \\
(\bar{x} \pm s)\end{array}$ & $\begin{array}{l}24 \text { horas } \\
(\bar{x} \pm s)\end{array}$ \\
\hline $\begin{array}{l}\text { Clivados } \\
\text { D-3 }\end{array}$ & $32,5 \pm 3,97^{\mathrm{a}}$ & $20,0 \pm 2,49^{b}$ & $11,5 \pm 1,08^{\mathrm{c}}$ & $3,4 \pm 0,84^{\mathrm{d}}$ & $2,4 \pm 0,51^{\mathrm{e}}$ & $2,7 \pm 0,82^{\mathrm{e}}$ \\
\hline $\begin{array}{l}8 \text { a } 16 \text { Células } \\
\text { D-4 }\end{array}$ & $24,3 \pm 2,62^{\mathrm{a}}$ & $14,5 \pm 2,06^{\mathrm{b}}$ & $6,9 \pm 0,73^{\mathrm{c}}$ & $2,6 \pm 0,51^{\mathrm{d}}$ & $1,4 \pm 0,69^{\mathrm{e}}$ & $1,9 \pm 0,73^{\mathrm{e}}$ \\
\hline $\begin{array}{l}\text { Mórula } \\
\text { D-5 }\end{array}$ & $19,9 \pm 2,68^{a}$ & $11,0 \pm 2,21^{b}$ & $3,8 \pm 0,63^{\mathrm{c}}$ & $2,4 \pm 0,51^{\mathrm{d}}$ & $1,0 \pm 0,81^{\mathrm{e}}$ & $0,7 \pm 0,67^{\mathrm{e}}$ \\
\hline $\begin{array}{l}\text { Blastocisto } \\
\text { D-8 }\end{array}$ & $9,14 \pm 2,44^{\mathrm{a}}$ & $4,16 \pm 0,96^{\mathrm{b}}$ & $2,53 \pm 1,25^{\mathrm{c}}$ & $1,58 \pm 0,51^{\mathrm{d}}$ & $0,68 \pm 0,67^{\mathrm{e}}$ & $0,20 \pm 0,42^{f}$ \\
\hline $\begin{array}{l}\text { Blastocisto } \\
\text { (Apoptose) }\end{array}$ & $9,18 \pm 0,56^{\mathrm{a}}$ & $13,04 \pm 0,51^{\mathrm{b}}$ & $18,51 \pm 0,52^{\mathrm{c}}$ & $31,25 \pm 0,52^{\mathrm{d}}$ & $71,42 \pm 0,52^{\mathrm{e}}$ & $100 \pm 0,42^{f}$ \\
\hline
\end{tabular}

\section{DISCUSSÃO}

EDWARDS \& HANSEN (1997), JU et al. (1999), ROTH \& HANSEN (2004), TSENG et al. (2004) e ROTH (2008) demonstraram por que, em bovinos, alterações no microambiente do oócito, in vivo e in vitro, provocadas pelo estresse térmico, afetam a viabilidade e a cinética de desenvolvimento embrionário.

O efeito do estresse térmico sobre os oócitos e embriões de mamíferos in vitro é dependente da temperatura e da duração da hipertermia. JU et al. (1999) relataram que a temperatura de $43^{\circ} \mathrm{C}$ reduz tanto a competência dos oócitos quanto o desenvolvimento embrionário bovino, mesmo com tempo de exposição de apenas 45 minutos. Neste trabalho, a escolha do tempo de exposição ao estresse térmico foi baseada em estudos anteriores de JU \& TSENG (2004) e de PAYTON et al. (2011), que demonstraram a susceptibilidade do oócito ao estresse térmico de $41^{\circ} \mathrm{C}$ sob diferentes intervalos de tempo. Além disso, a temperatura de $41^{\circ} \mathrm{C}$ reflete o valor médio de temperatura corporal aferida em animais expostos ao estresse térmico in vivo (RIVERA \& HANSEN, 2001). Os dados aqui obtidos corroboram as observações de que a maturação dos gametas foi reduzida proporcionalmente à duração de exposição ao estresse térmico de $41^{\circ} \mathrm{C}$.

O intervalo entre a maturação do oócito e a primeira clivagem é, segundo EALY et al. (1995), o período mais susceptível aos efeitos do estresse calórico no desenvolvimento embrionário e, após a ativação do genoma, o embrião torna-se mais resistente ao estresse (EDWARDS \& HANSEN, 1997; JU et al., 1999). Neste trabalho, o estresse térmico durante a maturação dos oócitos, mesmo após períodos mais curtos de incubação, evidenciou efeito acentuado sobre o desenvolvimento embrionário. A redução na produção in vitro de embriões até o estádio de mórula foi proporcional à duração do estresse térmico, exceto entre 18 e 24 horas de incubação, que tiveram taxas semelhantes da clivagem até a fase de mórula. Esse fato sugere que o período de maturação nuclear dos oócitos seja crítico para a susceptibilidade do gameta ao estresse térmico (TSENG et al., 2004). Todavia, os grupos de 18 e 24 horas de estresse diferiram na produção de blastocistos, possivelmente devido à qualidade destes embriões.

$\mathrm{O}$ estresse térmico induz a apoptose dos oócitos e embriões (EDWARDS \& HANSEN, 1997; ROTH \& HANSEN, 2004). A apoptose tem um efeito direto sobre a viabilidade dos embriões, pois, com a inibição da atividade das caspases do tipo II, a taxa de clivagem é recuperada após o estresse térmico em bovinos (ROTH \& HANSEN, 2004). Quanto à qualidade dos embriões deste trabalho, o percentual de blastômeros apoptóticos produzidos, a partir de oócitos expostos ao estresse térmico com tempos de exposições de 6 e 12 horas, assemelha-se aos de PAULA-LOPES \& HANSEN (2002a), obtidos em bovinos após exposição a $41^{\circ} \mathrm{C}$ por 9 horas. Esses autores afirmam também que é possível observar maior incidência de apoptose após estresse mais severo, comprometendo o desenvolvimento embrionário, como observado neste estudo, durante os períodos de incubação de 18 e 24 horas, em que a apoptose nos blastocistos chegou a 71,42 e 100\%, respectivamente.

A indução da apoptose após o choque térmico em bovinos e outros mamíferos foi aqui 
observada em embriões ovinos in vitro, sugerindo que a baixa viabilidade dos embriões expostos à hipertermia no trato reprodutivo feminino pode ser uma causa de perdas gestacionais durante o período pré-implantacional na espécie ovina. O melhor entendimento das respostas fisiológicas das células, gametas e embriões submetidos ao estresse térmico pode permitir o desenvolvimento de protocolos para a produção de embriões que melhor resistam ao estresse térmico in vitro e in vivo (WANG et al., 2009; ANDREU-VAZQUEZ et al., 2010; SHEHABEL-DEEN et al., 2010; PAYTON et al., 2011). Por exemplo, a adição de retinóides melhora a maturação in vitro dos oócitos expostos ao estresse térmico (LAWRENCE et al., 2004; MAYA-SORIANO et al., 2012).

\section{CONCLUSÃO}

Os resultados permitem concluir que a duração de exposição ao estresse calórico durante a maturação in vitro de oócitos ovinos é inversamente proporcional à quantidade e à qualidade dos embriões produzidos in vitro.

\section{AGRADECIMENTOS}

Ao Conselho Nacional de Desenvolvimento Científico - CNPq, à Fundação de Amparo a Ciência e Tecnologia do Estado de Pernambuco - FACEPE e à Empresa Suimax pelo suporte para a condução desta pesquisa. A M. T. Moura, bolsista CNPq.

\section{REFERÊNCIAS}

ANDREU-VAZQUEZ, C.; LOPEZ-GATIUS, F.; GARCIA-ISPIERTO, I.; MAYA-SORIANO, M.J.; HUNTER, R.H.F.; LOPEZ-BEJAR, M. Does heat stress provoke the loss of a continuous layer of cortical granules beneath the plasma membrane during oocyte maturation? Zygote, v.18, n. 4, p.293-299, 2010.

BADINGA, L.; COLLIER, R.J.; THATCHER, W.W.; WILCOX, C.J. Effects of climatic and management factors on conception rate of dairy cattle in subtropical environment. Journal of Dairy Science, v.68, p.78-85, 1985.

CHIAMENTI, A.; FILHO, C.R.; MOURA, M.T.; PAULA-LOPES, F.F.; NEVES, J.P.; NETO, C.C.; GON"CALVES, P.B.; LIMA, P.F.; OLIVEIRA, M.A. Use of retinyl acetate, retinoic acid and insulin-like growth factor-I (IGF-I) to enhance goat embryo production. Acta Veterinaria Hungarica v.61, p.116124, 2013.

EALY, A.D.; HOWELL, J.L.; MONTERROSO, V.H.; ARÉCHIGA, C.F.; HANSEN, P.J. Developmental changes in sensitivity of bovine embryos to heat shock and use of antioxidants as thermoprotectants. Journal of Animal Science, v.73, p.1401-1407, 1995.

EDWARDS, J.L.; HANSEN, P.J. Differential responses of bovine oocytes and preimplantation embryos to heat shock. Molecular Reproduction and Development, v.46, p.138-145, 1997.

EDWARDS, J.L.; BOGART, A.N.; RISPOLI, L.A.; SAXTON, A.M.; SCHRICK, F.N. Developmental competence of bovine embryos from heat-stressed ova. Journal of Dairy Science, v.92, p.563-570, 2009.

HANSEN, P.J. Effects of heat stress on mammalian reproduction. Philosophical Transactions of The Royal Society Biological Sciences, v. 364, p. 3341-3350, 2009.

INMET. Instituto Nacional de Meteorologia. Disponível em:

<http:www.inmet.gov.br/html/prev climatica tempo/prog nostico>. Acesso em: 23 abr. 2009.

JU, J.C.; PARKS, J.E.; YANG, X. Thermotolerance of IVM-derived bovine oocytes and embryos after shortterm heat shock. Molecular Reproduction and Development, v.53, p.336-340, 1999.

JU, J.C.; TSENG, J.K. Nuclear and cytoskeletal alterations of in vitro matured porcine oocytes under hyperthermia. Molecular Reproduction and Development, v.68, p.125-133, 2004.

KESKINTEPE, L.; SIMPLICIO, A.A.; BRACKETT, B.G. Caprine blastocyst development after in vitro fertilization with spermatozoa frozen in different extenders. Theriogenology, v.49, n.7, p.1265-1274, 1998.

LAWRENCE, J.L.; PAYTON, R.R.; GODKIN, J.D.; SAXTON, A.M.; SCHRICK, F.N.; EDWARDS, J.L. Retinol improves development of bovine oocytes compromised by heat stress during maturation. Journal of Dairy Science, v.87, p.2449-2454, 2004.

MAYA-SORIANO, M.J.; TABERNER, E.; LOPEZBEJAR, M. Retinol improves in vitro oocyte nuclear maturation under heat stress in heifers. Zygote, p.1-8, $2012 . \quad$ Disponível em: http://dx.doi.org/10.1017/S0967199412000135. Acesso em 23 de setembro de 2013.

PAULA-LOPES, F.F.; HANSEN, P.J. Apoptosis is an adaptative response in bovine preimplantation embryos that facilitates survival after heat shock. Biochemical Biophysical Research Communications, v.295, p.37-42, 2002a.

PAULA-LOPES, F.F.; HANSEN, P.J. Heat ShockInduced Apoptosis in Preimplantation Bovine Embryos. Is a Developmentally Regulated Phenomenon. Biology of Reproduction, v.66, p.1169-1177, 2002b.

PAYTON, R.R.; RISPOLI, L.A.; SAXTON, A.M.; EDWARDS, J.L. Impact of heat stress exposure during meiotic maturation on oocyte, surrounding cumulus cell, and embryo RNA populations. Journal of Reproduction and Development, v.57, n.4, 481-491, 2011. 
RIVERA, R. M.; HANSEN, P. J. Development of cultured bovine embryos after exposure to high temperatures in the physiological range. Reproduction, v.121, p.107-115, 2001.

ROTH, Z.; HANSEN, P. J. Involvement of apoptosis in disruption of developmental competence of bovine oocytes by heat shock during maturation. Biology of Reproduction, v.71, p.1898-1906, 2004.

ROTH, Z. Heat stress, the follicle, and its enclosed oocyte: mechanisms and potential strategies to improve fertility in dairy cows. Reproduction in Domestic Animals, v.43, Suplemento 2, p. 238-244, 2008.

SHEHAB-EL-DEEN, M.A.M.M.; LEROY, J.L.M.R.; FADEL, M.S.; SALEH, S.Y.A.; MAES, D.; VAN SOOM, A. Biochemical changes in the follicular fluid of the dominant follicle of high producing dairy cows exposed to heat stress early post-partum. Animal Reproduction Science, v.117, p.189-200, 2010.

SIMPLÍCIO, A. A.; FREITAS, V. J. F.; FONSECA, J. F. Biotécnicas da reprodução como técnicas de manejo reprodutivo em ovinos. Revista Brasileira de Reprodução Animal, v.31, n.2, p.234-246, 2007.

TSENG, J.K.; CHEN, C.H.; CHOU, P.C.; YEH, S.P.; JU, J.C. Influences of follicular size on parthenogenetic activation and in vitro heat shock on the cytoskeleton in cattle oocytes. Reproduction in Domestic Animals, v.39, p.146-153, 2004.

WANG, J.Z.; SUI, H.S.; MIAO, D.Q.; LIU, N.; ZHOU, P.; GE, L.; TAN, J.H. Effects of heat stress during in vitro maturation on cytoplasmic versus nuclear components of mouse oocytes. Reproduction, v.137, p.181-189, 2009. 